\title{
A MULTIMEDIA-RICH PLATFORM TO ENHANCE STUDENT ENGAGEMENT AND LEARNING IN AN ONLINE ENVIRONMENT
}

\author{
T. Scott Bledsoe \\ Azusa Pacific University \\ Bruce D. Simmerok \\ Azusa Pacific University
}

\begin{abstract}
Utilizing multimedia tools, such as videos and audio clips, can be an effective way to promote student learning and engagement in online settings. This study explores the implementation of a photo-rich comprehensive counseling center environment through which students of a semester-long online graduate psychology class learned about important research methodology concepts. Student feedback is provided along with implications for student learning in future online course endeavors. This multimedia course design was the recipient of the 2013 Sloan-C Effective Practices Award.
\end{abstract}

\section{KEY WORDS}

Multimedia, online classroom, student learning, mock counseling center, research methodology, web design.

\section{INTRODUCTION}

Educational institutions often champion online learning as a viable supplement to face-to-face instruction for their students. In promoting web-based programs, many institutions cite studies that have consistently shown the effectiveness in teaching students across a range of disciplines online [15]. Though students tend to prefer in-class schooling over its online counterpart, the advent of new multimedia features, such as virtual rooms, videos, photos, and audio clips, may ultimately lead to increased student acceptance of this instructional format. Citing its environment of virtual learning with a broad range of modalities from which to choose, McFarlane [12] noted that "the [media-filled] playgrounds of today's generations and this fact makes them ideal as platforms for educating today's and tomorrow's youth" (p. 5).

\section{A. The Online Learning Paradigm}

Online education, also called distance learning and Internet learning, can be defined as the process of providing systematic training to students in a given area of study within a web-based format. The vehicle for delivery of this platform, referred to as "educational cyberspace" [12] includes all testing procedures, lesson plans, administration of grades, and communication with instructors. A program that provides the framework through which students complete their coursework (e.g., Blackboard, Sakai) operates within a virtual learning environment [4].

Online learning systems have been scrutinized for their educational value in academic settings. In a metaanalysis of 50 studies conducted between 1994 and 2006 that compared online to face-to-face classroom formats, it was found that "students in online conditions performed modestly better, on average, than those learning the same material through traditional face-to-face instruction" [15]. Factors that contributed to greater effect sizes included types of knowledge tested, strength of the study design, and instructional approach. McFarlane [12] noted that a determining factor for implementing successful online programs was organization structure and the adherence to consistent rules in addition to a chain of 
command and teamwork among instructors, students, and technical support officials that was conducive to student learning.

Some online settings support computer-simulated learning in which participants are immersed in scalable 3D settings and navigate through alternate worlds [14], a concept popularly known as virtual reality. One example can be found in the computer program, Second Life, which invites constructivist-based, studentcentered learning [3] and allows participants to design and manage avatars that interact with each other in real time $[5,7,9]$.

The virtual world program, Second Life, was created in 2003 and by the end of the decade, many educational institutions bought and designed their own virtual campuses that were often located on elaborate 3D islands within the program $[5,7]$. Using their avatars, students visited the campuses, which provided resources such as informational brochures and lectures in the form of downloadable PowerPoint presentations. Yet since its inception, the program has been challenged by design flaws that make avatar control and interaction difficult to manage [5]. Sizable hardware requirements for Second Life have created additional problems for many students, resulting in frequent program freezes and computer reboots. Subscription fees and costs of creating and maintaining virtual campuses are sometimes prohibitive, and their academic benefits have yet to be proven, making the program questionable for efficient virtual online learning.

A practical alternative to Second Life exists in the form of augmented reality (AR), a variation of virtual reality in which users utilize "virtual objects superimposed upon or composited with the real world" [1]. For instance, in an AR setting a photo of a classroom on a course website could be enhanced with a virtual book on which online students could click to access instructions. As such, "AR supplements reality instead of completely replacing it" (p. 356). Because this definition is more compatible with the current study, all references to online multimedia environments will subsequently refer to augmented as opposed to virtual reality.

\section{B. Multimedia Tools to Supplement Online Learning}

Students utilize technology when they communicate through social networking or share videos and information with others via their smartphones. Many creators of online teaching programs also seek to incorporate popular technology to promote learning-based agendas. Kumar [10] claimed that student engagement in online environments was heightened when there was evidence of "effective and engaging multimedia resources to scaffold and anchor purposeful and active learning" (p. 6). Course instructors may thus seek to integrate socially sanctioned platforms into online settings in a way that promotes effective learning for their students.

Doolittle, as cited in Mandernach [11], defined multimedia as a "presentation of instruction that involves more than one delivery media, presentation mode, and/or sensory modality" (p. 2). Compiling the right tools for a successful multimedia environment may thus be an important step in promoting student learning. Miller [13] suggested using an even blend of media components that were tailored to the course and to the profession of study. He recommended supplementing the required text with video segments, audio clips, and interaction with social media (e.g., Facebook) to promote student collaboration and feedback.

When utilizing multimedia in web-based course delivery, Mandernach [11] advocated using instructorpersonalized multimedia components that promote collaboration in the often "faceless environment of online learning" (p. 5). In a study involving online students of a general psychology course taught across sequential terms, the author utilized weekly videos and audio-based PowerPoint presentations and designated specific times for e-mail and chat with students. She concluded that tailoring an interactive course protocol with a consistent multimedia presence created a high level of engagement and a strong atmosphere for learning, as evidenced by positive qualitative and quantitative student feedback at the end of the course. Additional successful multimedia-based online programs focused on language instruction $[2,6]$ and the teaching of data structures [8].

Learning strategies that incorporate multimedia in significant ways may become more prominent in future 
online course designs. Yet more data is needed in order for academic institutions to actively promote this idea. The current study attempts to achieve this goal by promoting dynamic learning of course content through an environment that is both stimulating and practical. The research questions for this study are as follows: In what ways can multimedia environments enhance student engagement? How can multimedia environments promote student learning?

\section{METHOD}

A website with a strong multimedia component was created to enhance student learning of graduate psychology in an existing online research methodology class. In developing the site, the creators envisioned moving beyond a traditional online format to provide students with a hands-on feel for research as it applied to their field of study. The designers utilized the Sakai web platform to showcase a mock community counseling center environment replete with a virtual office, therapy rooms, and a classroom, which featured assignments and instructional videos. During the spring of 2013, 59 students in four separate sections were enrolled in the new photo-rich course. At periodic points in the semester, they provided feedback about their experiences of navigating the online site as they learned research-based concepts.

In developing the multimedia aspect of the course, the site creators, one a web designer and the other an instructor of the class, took photos of various rooms inside a local community counseling center. Ten of the photos were eventually assembled as templates for the online environment, and a web design program, Dreamweaver, was used to create a framework for easy navigation of the course. To link the rooms together, the main office photo was modified to represent a visual hub for the center, which featured a directory of each room, a course calendar, and links to the course syllabus (figure 1). The designers incorporated a photo map for easy access to each of the available rooms on the website and FAQs about the course and the instructor's bio and hours of availability were also provided.

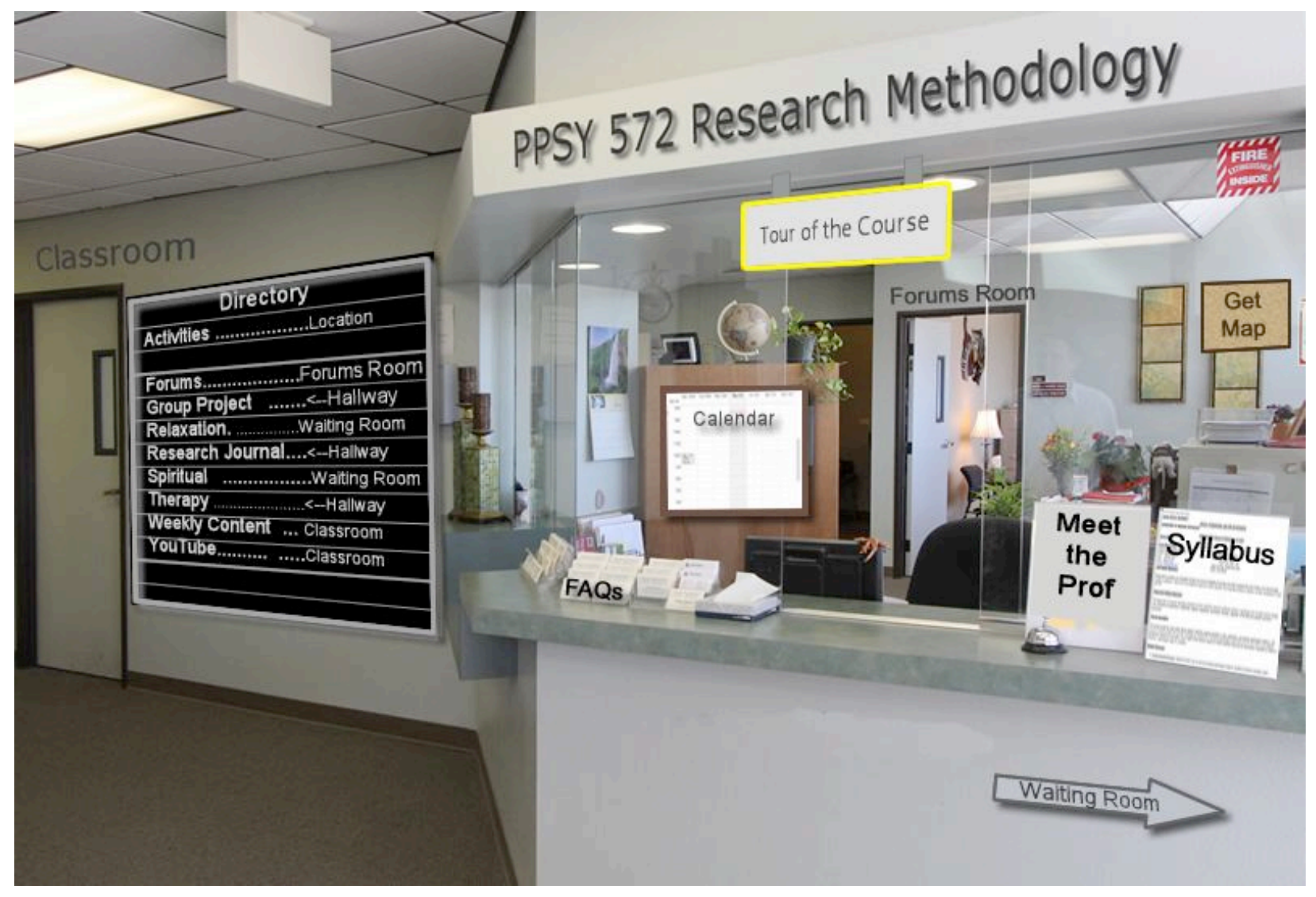


Figure 1. Main Office of the Mock Community Counseling Center

The classroom photo offered students a visual prompt for all course assignments. By clicking on a whiteboard on which each session was listed, students ascertained their weekly tasks. During the first week of the semester, for example, students clicked "Session 1" and were linked to a supplementary classroom that contained the assignments for that week (figure 2). The classroom photo also featured a wall-mounted television set that linked directly to a series of instructional videos based on course assignments. Each session-based classroom also contained a television set which, when clicked, offered 10-minute videos of research lessons and assignments provided by the course instructor.

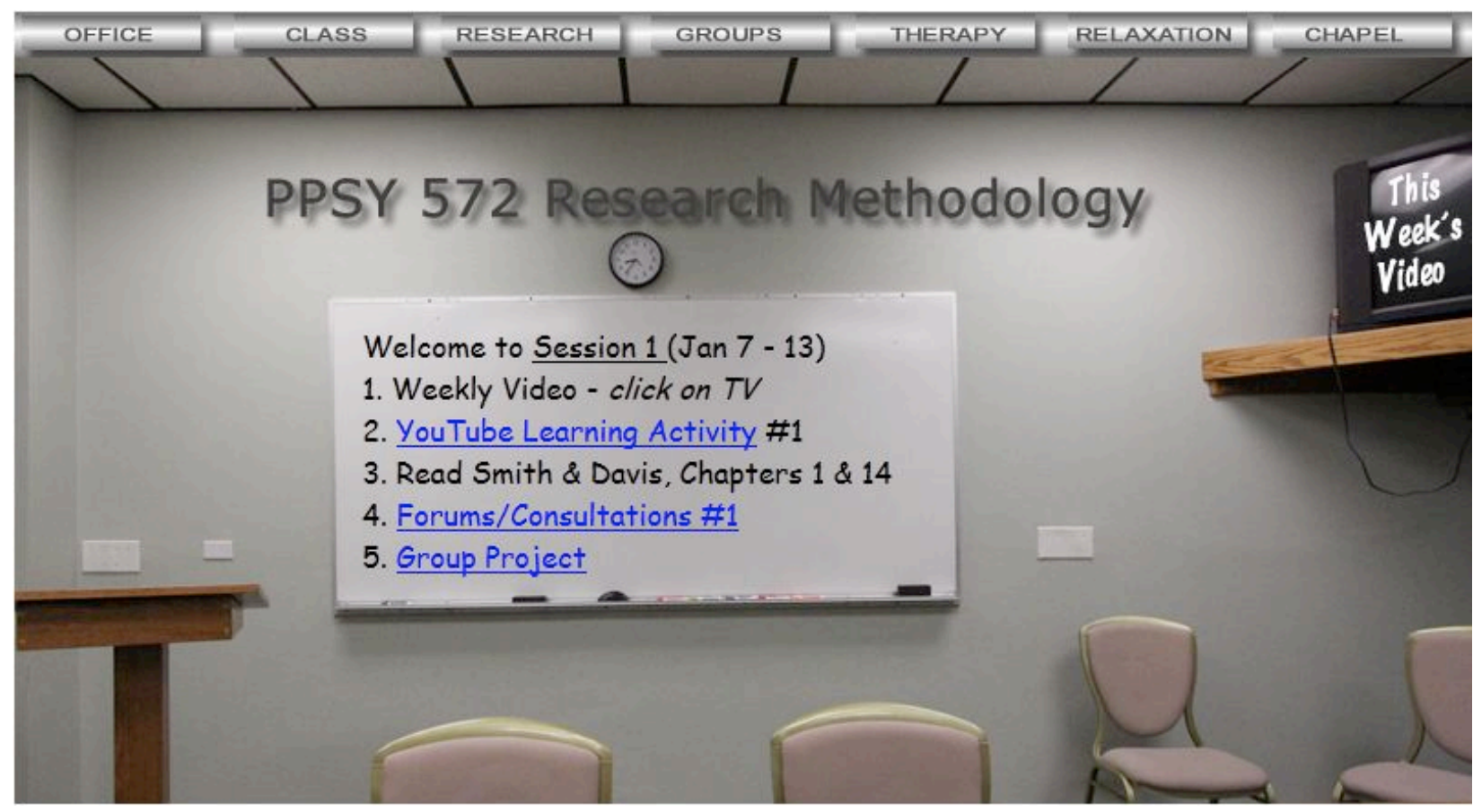

Figure 2. Classroom for Session 1

Additional rooms provided visual cues and instructions for completing tasks, such as creating therapy treatment plans, reviewing research articles, and participating in discussion threads. A waiting room offered a coffee table that linked directly to helpful resources for students, and a group room featured instructions for a semester-long group assignment. To promote student self-care, a relaxation room provided soothing sounds and prompts. Each room also offered audio recordings of former students discussing ideas for successfully completing course assignments. Student photos accompanied the recordings and by directly clicking on the photos, site visitors accessed helpful hints of previous students from the course. The most elaborate visual and auditory display appeared in the Group Room in which 12 student photos were assembled to provide auditory instructions on group project assignments throughout the semester (figure 3). Because students worked in groups to complete the semester-long project, the room also served to build a sense of community among current and former members of the class. 


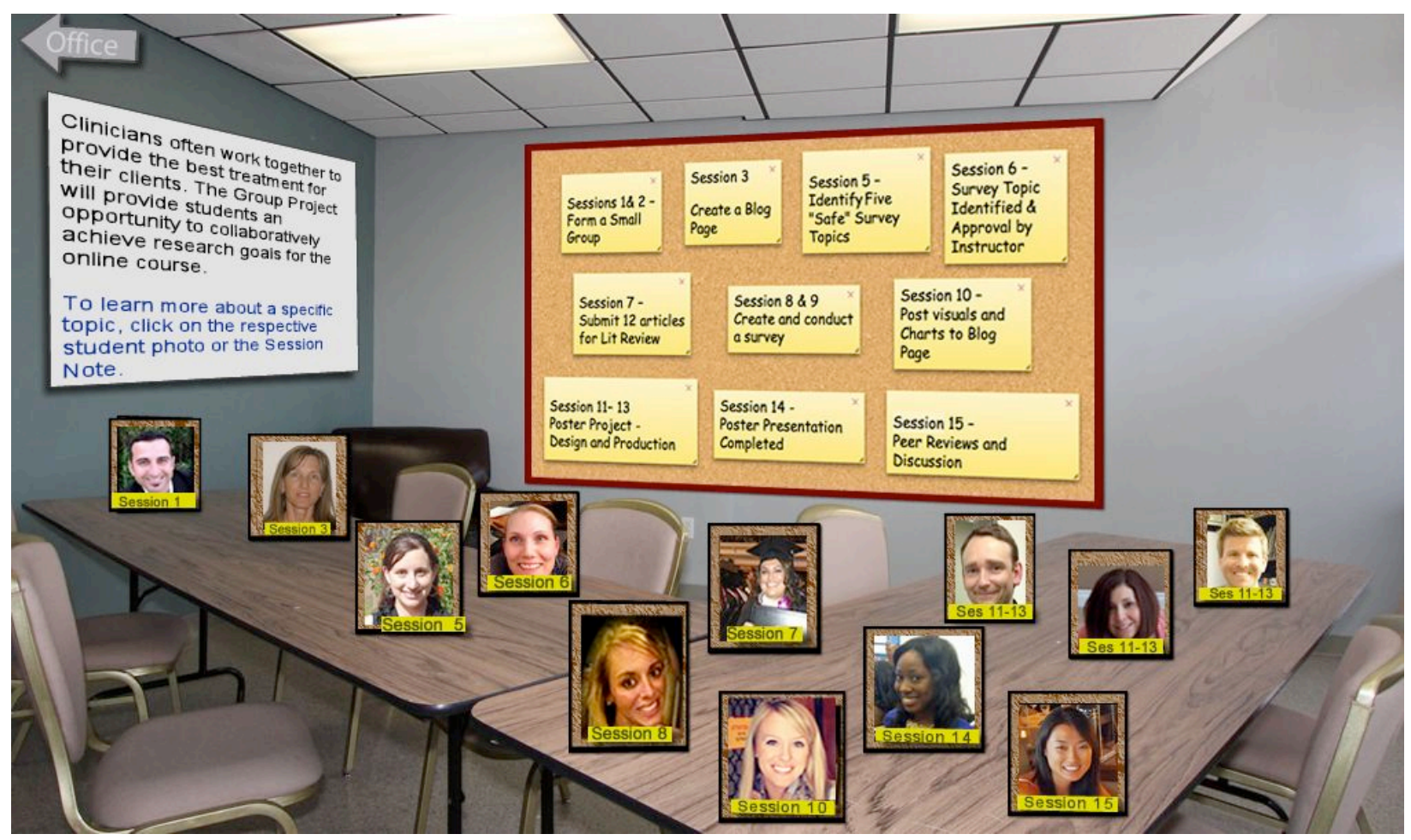

Figure 3. Group Room

The course designers utilized resource tabs from the Sakai web format to promote learning concepts in the counseling center environment. The Assignments tab accessed weekly assignments and quizzes, research article reports, and treatment plan activities. The Forums tab provided student access to topical discussions about research. Specific rooms (e.g., the Forums Room) were also created to help students understand the purpose of each assignment. For the Resources tab, a Doc Sharing folder was created in which important and supplemental course documents were stored. Students sent comments and concerns to the instructor by utilizing the Messages tab and a chat tool. All assignments were listed in the course syllabus and explained in weekly instructional videos accessed by clicking on the television in the classroom (figure 2). Quizzes and reports were graded by the instructor and posted to the Sakai Gradebook.

The instructor invited student feedback throughout the course, and during the sixth week, a SurveyMonkey questionnaire was distributed in order to evaluate student experiences of the online class. Six items specifically addressed their level of satisfaction with the mock community counseling center environment (table 1). Later in the semester, students were asked to provide input on ways that the virtual counseling center environment could be improved upon to augment their learning of research concepts.

\section{RESULTS}

As part of the SurveyMonkey questionnaire, students were asked to rate their experiences of the online research methodology course on a scale from one to five, with five representing a high degree of satisfaction. For items that addressed the mock counseling center environment specifically, $76 \%$ of the students agreed or strongly agreed that the online counseling center helped them learn in an online setting, and $71 \%$ endorsed the helpfulness of the environment in their learning of research concepts (table 1). Regarding specific virtual rooms of the course, the office and classroom generated the most positive responses ( $84 \%$ and $91 \%$ respectively), while opinions about the Group Room were less enthusiastic $(69 \%)$. When asked about their preference for online platforms, only $19 \%$ expressed either agreement or strong agreement that they preferred a more traditional online format for the course. 
\begin{tabular}{llll}
\hline Variable & $\% \sim$ Agree & $M$ & SD
\end{tabular}

Student impressions of the Mock Counseling Center experience (Scale $=1-5)$

$\begin{array}{llll}\text { The mock counseling center environment helps me } & 76 & 3.95 & 0.86\end{array}$ learn in an online setting.

The mock counseling center environment is helpful in my learning of research concepts.

The Office helps me to navigate the online course.

The Group Room photos and audio clips help me to understand the group projects more clearly.

The Classroom setting is nicely organized for aiding in my completion of weekly tasks.

I would prefer a more traditional online course format.

Table 1. SurveyMonkey Questionnaire (N=43)

In the online survey evaluations, students also provided qualitative feedback about their experience with the mock community counseling center. Positive comments included the following: "Compared to other online courses, I am surprised at how much I like the interactive setup of this course," "There are lots of resources at my fingertips," and "All the information and assignments that I have navigated through was well thought out and developed," and "I love the office and the amount of effort that [the instructor] has put into this online course to make it a good experience." Areas of concern were expressed as follows: "The pitfall of the website is that it is overwhelming with all of the different rooms and buttons. It's almost too complicated" and "I did find the Sakai classroom idea confusing at first. I am not sure how it could be clearer but I would like that." When asked to identify areas of growth for the website, several students responded with comments such as, "I think the site is outstanding, no ideas here ..." and "I'm not a big fan of online classes but this course is optimal for the material we are learning. I am enjoying it."

Quantitative data from the online class was compared over a four-year period with the class taught by the same instructor who utilized a similar format of course delivery (e.g., research-based article reviews and treatment plans, threaded discussions, weekly assignments, and a semester-long group project). The most recent year of data reflected the implementation of the mock counseling center setting (table 2).

Noteworthy findings included a significant increase in student endorsement of their enjoyment of the course $(79 \%$ as opposed to $65 \%$ the previous year) and reduced difficulty in understanding the online format of the course ( $12 \%$ vs. $42 \%$ the previous year). 
A Multimedia-Rich Platform to Enhance Student Engagement and Learning in an Online Environment

\begin{tabular}{llcccc}
\hline Variable & \multicolumn{5}{c}{ \% Agree } \\
\hline I am enjoying the Research Methodology & $\underline{2013}$ & $\underline{2012}$ & $\underline{2011}$ & $\underline{2010}$ \\
$\quad$ course so far. & 79 & 65 & 69 & 70 \\
I am learning important research concepts. & 86 & 86 & 84 & 83 \\
$\begin{array}{l}\text { I am having difficulty with the online format } \\
\text { of the course. }\end{array}$ & 12 & 42 & 10 & 17 \\
\hline
\end{tabular}

Table 2. Yearly Survey Comparisons

Student knowledge of research concepts was tested consistently throughout the online course. Through weekly quizzes and periodic reports, participants demonstrated their understanding of salient statistical information. For example, a multiple-choice quiz was presented in the final instructional video, and students were instructed to watch the film and submit their answers through the appropriate Sakai Assignment tab. Although the test was not standardized and results cannot be generalized beyond the current study, $96 \%$ of students scored $90 \%$ or higher, indicating at least a general understanding of research concepts presented in the course.

During the ninth week of the online course, students were asked to discuss ways that the mock community counseling center environment could be modified to improve their learning. The following ideas were suggested: "Perhaps add a checklist page or room, where the students could check off every step of what is due that week," and "Sometimes I wish that everything I needed for the week was in one place," and "Add a link to the office that will take us directly to the documents in the 'Doc Sharing' file under Resources. I've found these documents very helpful but sometimes I don't check this folder as frequently as I should." Students also expressed enthusiasm for the course format, as evidenced by the following comments: "I have taken several online classes between undergrad and grad school. I must say, this is by far the most interactive and positive experience that I have had with an online class. The "mock clinic' has been a great visual for me as I navigate Sakai," and "It almost feels like an in-person class in some ways!"

\section{CONCLUSION}

Online multimedia environments provide students with opportunities to learn and interact in a variety of ways $[11,12]$. Participants can learn important concepts by following course procedures enhanced by text, photos, videos, and a variety of computer programs; interacting with fellow students through e-mail, chat, and social network outlets; and completing such programs in the comfort of their own homes.

Research studies have demonstrated the effectiveness of utilizing such online classroom formats $[2,6,8$, 11] in educational settings.

In the current study, online students of a graduate psychology research methodology class completed a semester-long course in which they learned important statistical concepts, collaborated in groups on research-based projects, and demonstrated their knowledge through tests and quizzes. Students utilized photo-based rooms in a mock community counseling center environment to enhance their understanding and reinforce important research concepts. Throughout the course, students provided positive feedback about the multimedia setting, as evidenced by the following statement: "I love the office and the amount 
of effort that [the instructor] has put into this online course to make it a good experience." When compared to participants of the same course from earlier years (without the photo-rich environment), students graded their enjoyment of the course much higher (79\% vs. 65\% from the previous year), and their difficulty navigating the online environment as lower (12\% vs. $42 \%$ from the previous year).

Additionally, scores on quizzes and other course assignments indicate that students appeared to have learned effectively in the multimedia-focused environment.

In conclusion, online environments in which students interact with a range of multimedia tools can offer endless ways to learn and process new information while enjoying the benefits of technology. By creating a realistic setting, such as a mock community counseling center setting and linking rooms in ways that approximate reality and stimulate learning, students may demonstrate improvements in learning and increased enjoyment in the online course environment.

\section{REFERENCES}

1. Azuma, R.T. A Survey of Augmented Reality. Presence: Teleoperators and Virtual Environments, 6(4): 355-385 (August 1997). http://www.cs.unc.edu/ azuma/ARpresence.pdf.

2. Banados, E. A Blended-learning Pedagogical Model for Teaching and Learning EFL Successfully through an Online Interactive Multimedia Environment. CALICO Journal, 23(3): 533-550 (2006). https://www.calico.org/html/article_105.pdf.

3. Bledsoe, T.S., and Harmeyer, D. Constructivist-based Teaching in Second Life from a Student's Perspective: A Model Proposal. Journal of Educational Technology, 8(2): 34-41 (July 2011).

4. Dillenbourg, P. Virtual Learning Environments. Workshop presented at EUN Conference 2000, Geneva, Switzerland (2000).

5. Gorman, P. Has Second Life Lived Up to Expectations? Ariadne, 68 (March 2012). http://www.ariadne.ac.uk/issue68/gorman.

6. Huang, S.X., Dedegikas, C., and Walls, J. Using Multimedia Technology to Teach Modern Greek Language Online in China: Development, Implementation, and Evaluation. European Journal of Online and Distance Learning (September 2011). http://www.eurodl.org/?p=current\&article=417.

7. Inman, C., Wright, V.H., and Hartman, J.A. Use of Second Life in K-12 and Higher Education: A Review of Research. Journal of Interactive Online Learning, 9(1) (Spring 2010). http://www.ncolr.org/jiol/issues/pdf/9.1.3.pdf.

8. Junaidu, S. Effectiveness of Multimedia in Learning and Teaching Data Structures Online. Turkish Online Journal of Distance Education, 9(4): 97-107 (October 2008). http://files.eric.ed.gov/fulltext/EJ816483.pdf.

9. Kirriemuir, J. The Second Life of UK Academics. Ariadne, 53 (October 2007). http://www.ariadne.ac.uk/issue53/kirriemuir.

10. Kumar, M. A Critical Discourse in Multimedia Design: A Pedagogical Perspective to Creating Engaging Online Courseware. e-Journal of Instructional Science and Technology, 7(2) (2004). http://www.ascilite.org.au/ajet/e-jist/docs/Vol7_no2/FullPapers/Muthukumar_140105_2.pdf.

11. Mandernach, B.J. Effect of Instructor-personalized Multimedia in the Online Classroom. International Review of Research in Open and Distance Learning, 10(3): 1-19 (June 2009). http://www.irrodl.org/index.php/irrodl/article/view/606/1263.

12. McFarlane, D.A. A Comparison of Organizational Structure and Pedagogical Approach: Online Versus Face-to-face. The Journal of Educators Online, 8(1): 1-43 (January 2011). http://files.eric.ed.gov/fulltext/EJ917871.pdf.

13. Miller, M.V. Integrating Online Multimedia into College Course and Classroom: With Application to the Social Sciences. MERLOT Journal of Online Learning and Teaching, 5(2): 395-423 (June 2009). http://files.eric.ed.gov/fulltext/ED506000.pdf.

14. The New Media Consortium \& Educause Learning Initiative. The Horizon Report (2007). http://www.nmc.org/pdf/2007_Horizon_Report.pdf. 
15. U.S. Department of Education. Evaluation of Evidence-based Practices in Online Learning: A Meta-analysis and Review of Online Learning Studies (September 2010). http://www2.ed.gov/rschstat/eval/tech/evidence-based-practices/finalreport.pdf. 
